\title{
ANALYSIS OF HIGH COST OUTLIERS IN A POLISH REFERENCE HOSPITAL
}

\author{
Malgorzata Cyganska
}

\section{Introduction}

A concern over the raising resources consumed by health care costs has become widespread in many countries in recent years (Popesko, Papadaki, \& Novak, 2015). Health spending in Poland was $6.4 \%$ of GDP in 2013 , well below the OECD average of $8.9 \%$. In 2013 , per capita health spending in Poland has increased by a strong $3.8 \%$ in real terms, far above the average growth $(1.0 \%)$ across OECD countries (OECD Health Statistics 2015). Despite the fact, many hospitals still have negative financial results (Cyganska, 2015; Soltes \& Gavurova, 2014). The growth of financial problems of the health care sector entities contributed to the intensive search for its causes (Mączyński, 2011; Ministerstwo Zdrowia, 2004; Szetela, Lichwa, \& Korniejenko, 2011). One way is to improve the system of managing costs in the health care units. Many authors in their research analyzed the influence of different factors on the disease costs. (Hollenbeak, Murphy, Koenig, Woodward, Dunagan, \& Fraser, 2000; Uematsu, Kunisawa, Yamashita, \& Imanaka, 2015). Research conducted by Simrova, Bartak, Vojtisek and Rogalewicz (2014) has revealed that treatment costs significantly differ depending on the selected diagnostic and therapeutic procedures. Other researchers (Popesko, Papadaki, \& Novak 2015) highlights differences between the costs of individual patients under the same diagnosis and their differing demands on hospitals activities. Moreover, they confirmed that the reimbursement rates not always reflect the costs of treatment. The health technology assessment agencies, that play a vital role in the decision -making process, whether or not to reimburse given health technology, claims that in almost half of the recommendations takes into account the cost effectiveness issues.

Because of different factors influancing the healthcare costs, hospitals try to develop a systematic approach for identifying exceptional behaviors of certain patients' costs. Revealing them is important since it signifies that some extraordinary circumstances have occurred and shall deserve the attention of managers and doctors. Most of the studies identify the different causes of hospitalization as the factors that help in predicting the future costs (Dexter \& Lubarsky, 2004; Mapela, Mcmillanb, Frostc, Hurleyc, Picchic, Lydicka, \& Spencerd, 2005; Huang, Hu, Lee, Yang, Weng, Lin, \& Lai, 2013; Rimar \& Diers, 2006; Rottger, Scheller-Kreinsen, \& Busse, 2012; Taheri, Butz, \& Greenfield, 2000; Uematsu, Kunisawa, Yamashita, \& Imanaka, 2015). Some of the studies highlight the cost outliers (CO) or the length of stay (LOS) outliers as a specific category of patients worthy of attention (Cots, Elvira, Castells, \& Dalmau, 2000; Dahl, Wojtal, Breslow, Holl, Huguez, Stone, \& Korpi, 2012; Sackman \& Citrin, 2014). It was found that the probability of being the hospital CO is connected to LOS, acuity of illness, risk of mortality, social status, age, gender, type of admission, destination after discharge, Intensive Care Unit (ICU) stay and medical factors (Dahl et al., 2012; Pirson, Dramaix, Leclercq, \& Jackson, 2006). However since there are differences in case-mix and cost structures between hospitals, the proportion of $\mathrm{CO}$ and factors influencing the patient being $\mathrm{CO}$ may vary (Cooney, Haluck, Ku, Bass, Macleod, Brunner, \& Miller, 2003; Pirson, Dramaix et al., 2006). The aim of the study is to identify the factors facilitating identification of $\mathrm{CO}$ in one of the reference hospitals in northeast Poland.

\section{Material and Methods}

The analyzed hospital provides diagnostics, therapy, care, specialist advice, education, prevention, and health promotion. Between Januaryand June 2013, therewere 5,367 patients admitted to the Departments of Cardiology, 


\section{Ekonomika a management}

Laryngology, Ophthalmology, Nephrology, ICU, Gastroenterology, Orthopedics, Surgery, Neurosurgery, Gynecology, Endocrinology, Diabetology and Hematology. We reviewed all of the patients that were admitted to the hospital departments between January and June 2013, except newborns ( $N=462)$. Some of the patients were excluded from the analysis because of missing data $(n=335)$. Finally, we have included 4,570 patients for further assessment. The medical data for this analysis was obtained from the hospital's administrative database and accountancy and statistical data. The cost analysis was done retrospectively after the linkage the two databases.

\section{Tab. 1: Characteristics of hospitalized patients $(n=4,570)$}

\begin{tabular}{|c|c|}
\hline Patient charachteristics & mean $(s d)$ \\
\hline Age [years] & $56.54(18.21)$ \\
\hline LOS [days] & $5.39(6.65)$ \\
\hline Age group in years & n (\%) \\
\hline $18-30$ & $470(10.28)$ \\
\hline $31-50$ & $1,011(22.12)$ \\
\hline $51-70$ & $1,775(38.84)$ \\
\hline 71> & $1,077(23.56)$ \\
\hline Gender & n (\%) \\
\hline Female & $2,591(56.69)$ \\
\hline Male & $1,979(43.30)$ \\
\hline LOS group in days & n (\%) \\
\hline $1-2$ & $1,663(36.39)$ \\
\hline $3-4$ & $1,033(22.60)$ \\
\hline $5-7$ & $916(20.04)$ \\
\hline $8-10$ & $462(10.11)$ \\
\hline $11>$ & $496(10.85)$ \\
\hline Admission & n (\%) \\
\hline Planned & $2,382(52.12)$ \\
\hline Unplanned & $2,188(47.88)$ \\
\hline Reason of discharge & n (\%) \\
\hline Completed therapeutic process & $3,021(66.11)$ \\
\hline Directed to further treatment & $1,443(31.58)$ \\
\hline Death & $106(2.32)$ \\
\hline Department & n (\%) \\
\hline Surgical & $3,445(75.38)$ \\
\hline Nonsurgical & $1,125(24.62)$ \\
\hline Costs $(€)$ & median [IQR] \\
\hline Total Costs & $895.20[458.91-1,633.75]$ \\
\hline Direct Costs & $344.02[130.30-883.20]$ \\
\hline Indirect Costs & $380.44[193.40-774.30]$ \\
\hline
\end{tabular}


In studied hospital the allocation of hospital costs to patient-level costs involved 5 steps:

1. The allocation of costs to final, medical and non-medical cost support centers.

2. The allocation of non-medical (transportation, laundry) support costs centers costs to medical (laboratory, operating room) support and final (wards) cost centers.

3. Calculation of intermediate products costs (e.g. laboratory tests, diagnosis tests, surgical interventions).

4. Assigning intermediate products and administration costs to final cost centers.

5. Calculation of final products costs within direct costs (drugs, intermediate product costs) and overhead costs (based on the length of stay).
Cost in PLN were converted to euro on the basis of average exchange rate of NBP (Polish National Bank) from 30.09.2015 $(1 €=4.2386$ PLN).

To select the outliers, we used the interquartile method using the median and the interquartile distance (Stanisz, 2007). To select high outliers, the $75^{\text {th }}$ percentile $+1.5^{*}$ interquartile range was used. To identify the low outliers, we used the $25^{\text {th }}$ percentile $-1.5^{*}$ interquartile range. Because the rule $25^{\text {th }}$ percentile $-1.5^{*}$ interquartile range detected a negative trim-point in further analysis, we considered only high cost outliers.

We considered age, LOS, gender, type of admission, reason of discharge, and type of department as the possible factors that may influence the patient being a cost outlier.

\section{Tab. 2: Characteristics of cost outliers (CO) and inliers (CI)}

\begin{tabular}{|c|c|c|c|}
\hline Predictive factors & $\begin{array}{c}C O \\
N=433 \\
\end{array}$ & $\begin{array}{c}\mathrm{Cl} \\
\mathrm{N}=4,137\end{array}$ & p-Value \\
\hline Age [years] mean (s.d.) & $59.47(14.67)$ & $56.23(18.51)$ & $<0.0016^{*}$ \\
\hline \multicolumn{4}{|l|}{ Age n (\%) } \\
\hline$<56$ & $158(36)$ & $1,873(45)$ & \multirow{2}{*}{$<0.001^{* *}$} \\
\hline$>56$ & $275(64)$ & $2,264(55)$ & \\
\hline \multicolumn{4}{|l|}{ Gender n (\%) } \\
\hline Female & $175(40)$ & $2,416(58)$ & \multirow{2}{*}{$<0.001^{* *}$} \\
\hline Male & $258(60)$ & $1,721(42)$ & \\
\hline LOS [days] mean (s.d.) & $12.8(14.5)$ & $4.6(4.5)$ & $<0.001^{*}$ \\
\hline \multicolumn{4}{|l|}{ LOS n (\%) } \\
\hline$<$ Mean & $63(15)$ & $2,633(64)$ & \multirow{2}{*}{$<0.001^{* *}$} \\
\hline$>$ Mean & $370(85)$ & $1,504(36)$ & \\
\hline \multicolumn{4}{|l|}{ Type of admission n (\%) } \\
\hline Planned & $178(41)$ & $2,204(53)$ & \multirow{2}{*}{$<0.001^{* *}$} \\
\hline Unplanned & $255(59)$ & $1,933(47)$ & \\
\hline \multicolumn{4}{|l|}{ Reason of discharge $n(\%)$} \\
\hline Completed therapeutic process & $158(36)$ & $2,863(69)$ & \multirow{3}{*}{$<0.001^{* *}$} \\
\hline Directed to further treatment & $254(59)$ & $1,189(29)$ & \\
\hline Death & $21(5)$ & $85(2)$ & \\
\hline \multicolumn{4}{|l|}{ Department $n(\%)$} \\
\hline Surgical & $402(93)$ & $3,043(74)$ & \multirow{2}{*}{$<0.001^{* *}$} \\
\hline Nonsurgical & $31(7)$ & $1,094(26)$ & \\
\hline
\end{tabular}


Statistical analysis was carried out using StatSoft, Inc. (2011) STATISTICA, version 10. The analysis of contingency tables was executed with the Pearson's $\chi^{2}$-test. Continuous variables without normal distribution (LOS, age) were analyzed with the Mann-Whitney test. Univariate and multivariable logistic regression analysis were used to determine the predictors of $\mathrm{CO}$.

\section{Results}

On the studied population, the mean patient age was 56.5 years; men comprised $43.3 \%$ of the study sample. The mean and standard deviation of LOS were 5.39 and 6.65 days, respectively. Most of the patients were admitted to the hospital within planned admission (52.12\%) and were discharged from the hospital within 4 days $(58.99 \%)$. The main reason of the patients' discharge was completing the therapeutic process $(66.11 \%)$. Most of the patients have been cured in the surgical departments $(75.38 \%)$. The median and standard deviation of the total hospitalization costs, direct costs, and indirect costs were $€ 895.20$ (458.91-1,633.75); $€ 344.02$ (130.30-883.20); and €380.44 (193.40-774.30), respectively (Tab. 1).

On the studied population, 433 patients were identified as cost outliers (CO). They comprised $9.47 \%$ of the study sample. The average age of CO was $59.5(\mathrm{SD} \pm 14.7)$, the length of stay of $\mathrm{CO}$ was $12.8(\mathrm{SD} \pm 14.5)$. Most of outliers were men $(59 \%)$, directed to further treatment $(59 \%)$ and surgical patients. The profile of $\mathrm{CO}$ in all analyzed variables was statistically significantly different from the inlier patients (Tab. 2).

The status of the cost outliers in contrast to inliers was associated with older age, unplanned admission, being directed to further treatment after discharge from hospital, and being a surgical patient. The median total cost, direct costs, and indirect costs for $\mathrm{CO}$ was $€ 4,779.08$, $€ 2,758.49$ and $€ 1,755.28$, respectively (Tab. 3 ).

\begin{tabular}{|c|c|c|}
\hline Tab. 3: & $\begin{array}{l}\text { nge of total hospital costs } \\
\text { rs (CO) and inliers (CI) }\end{array}$ & ts and indirect costs \\
\hline Costs & CO median [range] $(€)$ & $\mathrm{Cl}$ median [range] $(€)$ \\
\hline Total costs & $4,779.08[3,944.89-6,040.47]$ & $809.90[423.36-1,346.16]$ \\
\hline Direct costs & $2,758.49[2,046.40-3,753.44]$ & $290.02[115.70-687.84]$ \\
\hline Indirect costs & $1,755.28[1,115.68-3,075.25]$ & 345.21 [180.47-640.63] \\
\hline
\end{tabular}

Source: own

CO accounted for almost $37 \%$ of total hospital costs, $40 \%$ of direct costs, and $34 \%$ of indirect costs. In univariate analysis, we found all analyzed variables as the independent factors on being the $\mathrm{CO}$ (Tab. 4).

In multivariate analysis, we found that age and type of admission doesn't increase a patient's probability of being $\mathrm{CO}$. We identified here gender, LOS, reason of discharge and type of department as the independent factors on being the $\mathrm{CO}$ (Tab. 5).

The probability of being the $\mathrm{CO}$ increased more than 13 times for patients that stayed in the hospital longer than 5 days (mean for all the patients). The probability of becoming a $\mathrm{CO}$ in surgical patients increased 6 times.

To determine the predictive value of the regression model we performed the receiver operating characteristic (ROC) analysis (Fig. 1). The area under the curve (AUC) for $\mathrm{CO}$ was
0.857 , what represents a good accuracy of the regression model.

In Tab. 6 we presented the $\mathrm{CO}$ and $\mathrm{Cl}$ by ICD 10 (International Classification of Diseases 10th Revision).

We have analyzed 4,570 patients, who suffered from 825 diseases classified by ICD 10. For further analysis we chose the diseases with the number of $\mathrm{CO}$ higher than $5(n=23)$. In the analysed group of diseases $93 \%(n=402)$ of the CO were surgery patients and only $7 \%$ ( $n=31$ ) were non-surgery patients. In none of the analyzed diseases, the number of nonsurgery outliers exceeded 1 . The most frequent disease associated with surgery cost outliers was atherosclerotic cardiovascular disease (I25.0), which constitutes $9 \%$ of all surgery CO. In terms of five diseases the $\mathrm{CO}$, occur more often than $\mathrm{Cl}$. It concerns coxarthrosis (M16), gonarthrosis (M17.0, M17.1), benign neoplasm 

a patient's probability of being cost outliers (CO)

\begin{tabular}{|c|c|c|c|}
\hline Variables & Adjusted OR & $(\mathrm{IC} * 95 \%)$ & p-Value \\
\hline \multicolumn{3}{|l|}{ Age } & \multirow{3}{*}{$<0.001$} \\
\hline$<56$ & 1 & & \\
\hline$>56$ & 1.61 & $(1.25-2.06)$ & \\
\hline \multicolumn{3}{|l|}{ Gender } & \multirow{3}{*}{$<0.001$} \\
\hline Female & 1 & & \\
\hline Male & 2.09 & $(1.64-2.66)$ & \\
\hline \multicolumn{3}{|l|}{ LOS } & \multirow{3}{*}{$<0.001$} \\
\hline$<$ Mean & 1 & & \\
\hline$>$ Mean & 1.18 & $(1.16-1.20)$ & \\
\hline \multicolumn{3}{|l|}{ Type of admission } & NS \\
\hline \multicolumn{3}{|l|}{ Reason of discharging (\%) } & \multirow{4}{*}{$<0.001$} \\
\hline Completed therapeutic process & 1 & & \\
\hline Directed to further treatment & 4.31 & $(3.38-5.53)$ & \\
\hline Death & 5.12 & $(2.80-9.35)$ & \\
\hline \multicolumn{3}{|l|}{ Department } & \multirow{3}{*}{$<0.001$} \\
\hline Nonsurgical & 1 & & \\
\hline Surgical & 6.03 & $(3.96-9.17)$ & \\
\hline
\end{tabular}

OR - Odds Ratio; IC - Interval Confidence; NS - not significant

${ }^{*} p$-Value - statistical significance for univariate logistic regression analysis.

\begin{tabular}{|c|c|c|c|}
\hline $\begin{array}{l}\text { Multivariate logist } \\
\text { a patient's probab }\end{array}$ & $\begin{array}{l}\text { analysis for sel } \\
\text { ost outliers (C) }\end{array}$ & ted factors inc & ing \\
\hline Variables & Adjusted OR & $(I C * 95 \%)$ & p-Value* \\
\hline \multicolumn{3}{|l|}{ Gender } & \multirow{3}{*}{$<0.001$} \\
\hline Female & 1 & & \\
\hline Male & 1.90 & $(1.51-2.40)$ & \\
\hline \multicolumn{3}{|l|}{ LOS } & \multirow{3}{*}{$<0.001$} \\
\hline$<$ Mean & 1 & & \\
\hline$>$ Mean & 13.79 & $(10.35-18.37)$ & \\
\hline \multicolumn{3}{|l|}{ Reason of discharge (\%) } & \multirow{4}{*}{$<0.001$} \\
\hline Completed therapeutic process & 1 & & \\
\hline Directed to further treatment & 4.15 & $(3.27-5.27)$ & \\
\hline Death & 5.79 & $(3.21-10.45)$ & \\
\hline \multicolumn{3}{|l|}{ Department } & \multirow{3}{*}{$<0.001$} \\
\hline Nonsurgical & 1 & & \\
\hline Surgical & 6.51 & $(4.4-9.62)$ & \\
\hline
\end{tabular}

${ }^{*} p$-Value - statistical significance for multivariate logistic regression analysis. 


\section{Fig. 1: ROC curve for the multivariate logistic regression model predicting CO}

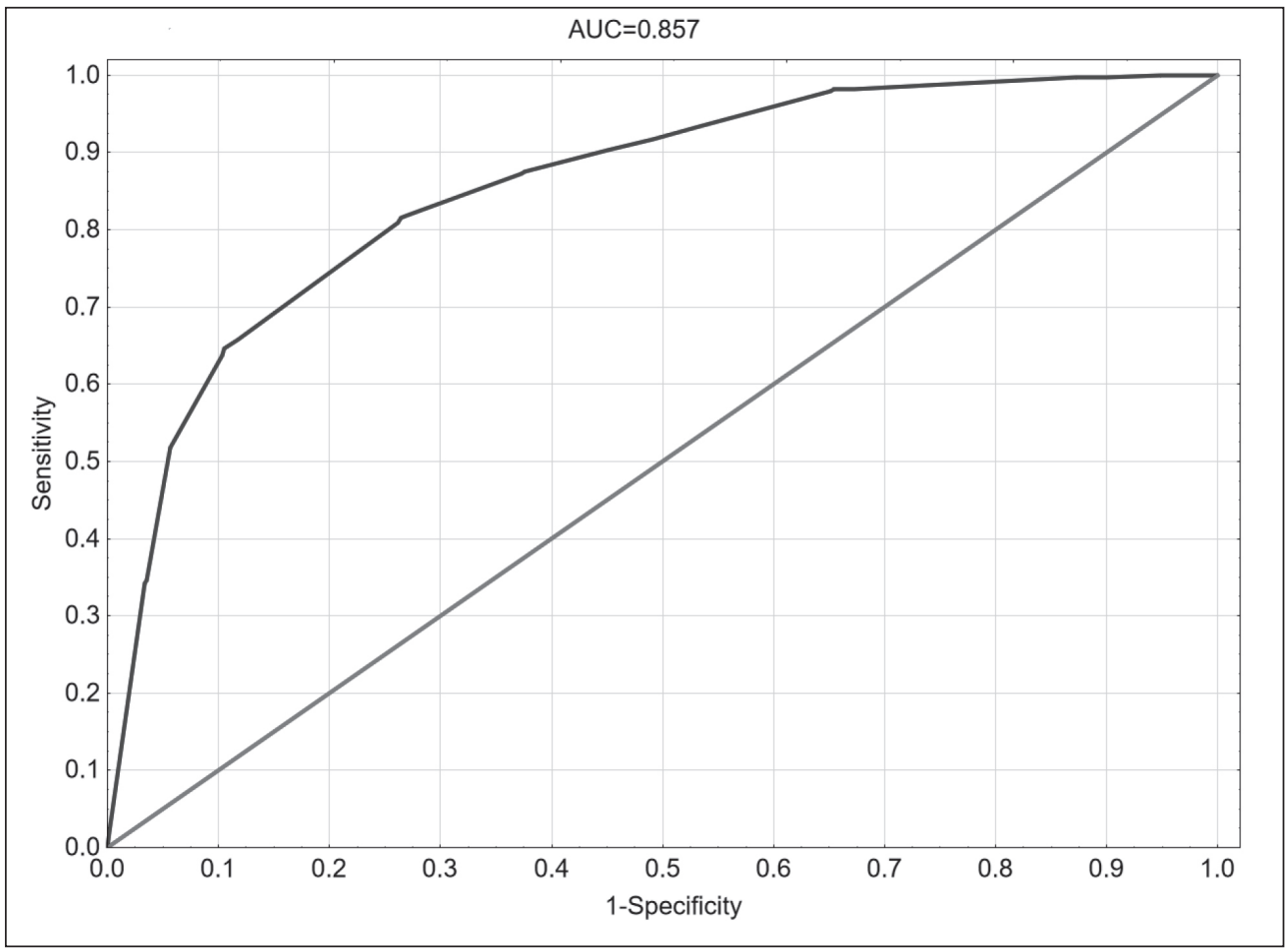

Source: own

of the brain and other parts of the central nervous system (D33.0), angina pectoris (I20.9) and abdominal aortic aneurysm (I71.4). In case of malignancy diseases of the larynx (C32.9), the ratio of cost outliers to cost inliers equaled 1. It confirms the previous findings that surgery patients are more likely to become cost outliers than non-surgery patients.

\section{Discussion}

In this study, we analyzed the factors facilitating the identification of patients being cost outliers. We have used factors available in the hospital database like age, gender, LOS, type of admission, reason of discharge.

In our research, the cost outliers comprised $9 \%$ of the study sample, which is similar to the previous analyses that reported $6 \%$ to $8 \%$ patients that can be identified as the high cost outliers (Huang et al., 2013), (Medicare Program, 2003), (Pirson, Dramaix et al., 2006;
Pirson, Martins, Jackson, Dramaix, \& Leclercq, 2006). The differences in percentage of cost outliers can be associated with methods of selecting cost outliers. For example Pirson, Dramaix et al. (2006) selected cost outliers, by the $75^{\text {th }}$ percentile $\pm 1,5^{*}$ interquartile range, Cooney et al. (2003) defined cost outliers as patients with hospital costs $>1$ standard deviation above the mean and Calver, Brameld, Preen, Alexia, Boldy and Mccaul (2006) chose the top $5 \%$ of patients ranked from highest to lowest total inpatient costs. In our study, the CO accounted for $33 \%$ of total hospital costs. We analyzed the Polish public reference hospital, which admits the most severe patients from the region. That is why the percentage of the costs related to $\mathrm{CO}$ seems to be high. However, previous studies reported that cost outliers in public general hospitals in Wallonia accounted for $22-30 \%$ of total hospital costs (Pirson, Martins et al., 2006). In public and private hospitals located in Western Australia, 


\begin{tabular}{|c|c|c|c|c|c|}
\hline \multirow[t]{3}{*}{ Tab. 6: } & \multicolumn{5}{|c|}{$\begin{array}{l}\text { Cost outliers }(C O) \text { by surgery }(\mathrm{S}) \text { and non-surgery }(\mathrm{NS}) \text { patients and inliers }(\mathrm{Cl}) \\
\text { by ICD-10 }\end{array}$} \\
\hline & \multirow[b]{2}{*}{ ICD 10} & \multirow{2}{*}{$\begin{array}{l}\mathrm{Cl} \\
\mathrm{N}=4,137\end{array}$} & \multicolumn{2}{|c|}{$\mathrm{CO}$} & \multirow{2}{*}{$\begin{array}{c}\mathrm{CO} / \mathrm{Cl} \\
{[\%]}\end{array}$} \\
\hline & & & $\begin{array}{c}S \\
N=402\end{array}$ & $\begin{array}{l}\text { NS } \\
N=31\end{array}$ & \\
\hline 125.0 & $\begin{array}{l}\text { Atherosclerotic cardiovascular disease, } \\
\text { so described }\end{array}$ & 212 & 36 & 0 & 16.98 \\
\hline M16.1 & Other primary coxarthrosis & 2 & 19 & 0 & 950 \\
\hline 170.2 & Atherosclerosis of arteries of extremities & 71 & 17 & 0 & 23.94 \\
\hline I20.9 & Angina pectoris, unspecified & 13 & 17 & 0 & 130.77 \\
\hline M51.1 & $\begin{array}{l}\text { Lumbar and other intervertebral disc } \\
\text { disorders with radiculopathy }\end{array}$ & 33 & 16 & 0 & 48.48 \\
\hline M16.0 & Primary coxarthrosis, bilateral & 0 & 14 & 0 & - \\
\hline 120.0 & Unstable angina & 40 & 11 & 0 & 27.5 \\
\hline D33.0 & Brain, supratentorial & 3 & 11 & 0 & 366.67 \\
\hline S06.5 & Traumatic subdural haemorrhage & 20 & 10 & 0 & 50 \\
\hline I21.1 & $\begin{array}{l}\text { Acute transmural myocardial infarction } \\
\text { of inferior wall }\end{array}$ & 39 & 9 & 0 & 23.08 \\
\hline M17.1 & Other primary gonarthrosis & 3 & 9 & 0 & 300 \\
\hline M51.2 & $\begin{array}{l}\text { Other specified intervertebral disc } \\
\text { displacement }\end{array}$ & 38 & 8 & 0 & 21.05 \\
\hline 150.1 & Left ventricular failure & 17 & 8 & 0 & 47.06 \\
\hline 121.0 & $\begin{array}{l}\text { Acute transmural myocardial infarction } \\
\text { of anterior wall }\end{array}$ & 32 & 8 & 0 & 25 \\
\hline I21.9 & Acute myocardial infarction, unspecified & 72 & 8 & 0 & 11 \\
\hline 171.4 & $\begin{array}{l}\text { Abdominal aortic aneurysm, without mention } \\
\text { of rupture }\end{array}$ & 6 & 7 & 0 & 117 \\
\hline M17.0 & Primary gonarthrosis, bilateral & 0 & 7 & 0 & - \\
\hline C32.9 & $\begin{array}{l}\text { Malignancy diseases of the larynx, } \\
\text { unspecified }\end{array}$ & 7 & 7 & 0 & 100 \\
\hline 099.1 & $\begin{array}{l}\text { Other diseases of the blood and blood- } \\
\text { forming organs and certain disorders } \\
\text { involving the immune mechanism } \\
\text { complicating pregnancy, childbirth } \\
\text { and the puerperium }\end{array}$ & 16 & 7 & 0 & 43.75 \\
\hline M50.1 & Cervical disc disorder with radiculopathy & 11 & 7 & 0 & 63.64 \\
\hline I25.1 & Atherosclerotic heart disease & 52 & 7 & 0 & 13.46 \\
\hline 170.9 & Generalized and unspecified atherosclerosis & 13 & 6 & 0 & 46.15 \\
\hline N18.0 & Chronic kidney disease & 49 & 5 & 1 & 12 \\
\hline- & Other & 3,388 & 148 & 30 & 10.47 \\
\hline
\end{tabular}


CO accounted for more than $38 \%$ (Calver et al., 2006). The differences in percentage of costs assigned to $\mathrm{CO}$ can be related to differences in hospitals and (omit but?) also to diversified models of costs accounting systems (Raulinajtys-Grzybek, 2014).

We presumed that because older patients remain in hospitals significantly longer than younger patients, they would use more hospital resources (Rimar \& Diers, 2006). However, we found that age is not associated with being the $\mathrm{CO}$. The same finding was reported in previous studies (Calver at al., 2006; Pirson, Dramaix et al., 2006). Seshamani and Gray (2004) reveal that remaining time to death is much more important than age when discussing the influence on the hospital costs. According to others, higher hospital costs for older people can be explained mostly by differences in patient comorbidities and complications (Uematsu, 2015). Thus, changes in the average age of hospitalized patients cannot be a justification for changes in the level of costs in the hospital.

Some of the studies highlighted that admission type has an influence on patient's costs; some of them did not reveal it (Brimhall, Dean, Hunt, Siegrist, \& Reiquam, 2003; Munoz, Zahtz, Lamantia, Chalfin, Lackner, \& Wise, 1989). In our study of multivariate logistic regression analysis, in contrast to univariate, the admission type was not predictor of being the CO. That can be associated with the strong correlation between type of admission and length of stay, which was also reported by Perry and Alshurafa (2010). This means that acute admitted patients contribute to higher resource utilization because of longer stay rather than the use of more cost-intensive procedures. This is consistent with Huang et al., (2013) study, who reported that length of stay is an important measure of resource utilization.

In accordance with the Omachnonu, Suthummanon, Akcin and Asfour (2004) study, we discovered that in terms of gender, men are positively correlated with higher costs utilization. It could be related to the fact that women are more aware of health matters than men and take better care of themselves (Dean, 1989). In addition, they visit physicians more often than men, resulting in earlier detection of health problems (Cockerham, 1998). This indicates a strong need for patient education, with special emphasis on men in terms of disease prevention. As reported by Sultz and
Young (2001) patients who are hospitalized in an earlier stage of a disease tend to have a shorter stay in hospital, facilitating in lower resource consumptions. Therefore, educational activities can help to reduce the proportion of readmissions, and in consequence, to lower the hospital costs.

The study revealed that the probability of being the $\mathrm{CO}$ increased more than 6 times for the surgical patients. This is consistent with the analysis of CO by ICD 10. The analysis revealed that almost all patients suffered from diseases related to high proportion of $\mathrm{CO}$, required surgery treatment.

The small number of analyzed factors leading to patient being $\mathrm{CO}$ is the main limitation of this study. We could not analyze medical factors such as complications due to the limitation of Polish hospital databases. However, similar analysis with additional explanatory factors derived from accessible hospital databases chosen by clinicians and managers working together could be used for $\mathrm{CO}$ identification. The study was carried out in only one hospital located in northeast Poland. According to our knowledge, this is the first study in the field within Poland, thus we chose to analyze primarily the patients' characteristics before concentrating on the diagnoses related groups (DRG).

\section{Conclusions}

Our study revealed that the small percentage of the patients is responsible for the significant level of costs. The median total cost for outliers is $€ 4,779.08$ and is almost 6 times higher than total cost for inliers $-€ 809.90$. The median direct costs for outliers is $€ 2,758.48$ and is even more than 9 times higher than for inliers - $€ 290.02$. This makes cost outliers worth special attention. The patient's characteristics can influence the costs in the direct or indirect way (by length of stay). There are several applications for the knowledge obtained from such analysis, namely identifying the patients who may require special funding on the basis of real cost; finding the explanatory factors for extreme total costs. Managers can be interested in extremely high costs and their association with medical procedures and LOS. Thus, this study can contribute to the knowledge of managers about the nature of cost outliers and identify ways to prevent future instances. Such information can also be used for health care financing policy 
and for preparing hospital procedure guidelines. Detecting $\mathrm{CO}$ and the factors influencing it can be especially valuable in the financing systems where high costs outliers are separately paid or in systems where hospitals can incur financial penalties for cost outliers. Analyzing of cost outliers is important, as it helps to comprehend hospital costs.

\section{References}

Brimhall, B. B., Dean, T., Hunt, E. L., Siegrist, R. B., \& Reiquam, W. (2003). Age and Laboratory Costs for Hospitalized Medical Patients. Archives of Pathology \& Laboratory Medicine, 127(2), 169-177. doi:10.1043/00039985(2003)127<169:AALCFH>2.0.CO;2.

Calver, J., Brameld, K. J., Preen, D. P., Alexia, S. J., Boldy, D. P., \& Mccaul, K. A. (2006). High-cost users of hospital beds in western Australia: a population - based record linkage study. The Medical Journal of Australia, 184(8), 393-397.

Cockerham, W. C. (1998). Medical Sociology (7th ed.). New Jersey: Prentice Hall.

Cooney, R. N., Haluck, R. S., Ku, J., Bass, T., MacLeod, J., Brunner, H., \& Miller, C. A. (2003). Analysis of cost outliers after gastric bypass surgery: what can we learn? Obesity surgery, 13(1), 29-36. doi:10.1381/096089203321136557.

Cots, F., Elvira, D., Castells, X., \& Dalmau, E. (2000). Medicare's DRG-weights in a European environment: the Spanish experience. Health Policy, 51(1), 31-47. doi:10.1016/S01688510(99)00074-3.

Cyganska, M. (2015). The usage of financial analysis to evaluate the hospitals financial performance - selected problems. Research Papers of Wroclaw University of Economics, 388, 363-373.

Dahl, D., Wojtal, G. G., Breslow, M. J., Holl, R., Huguez, D., Stone, D., \& Korpi, G. (2012). The High Cost of Low-Acuity ICU Outliers. Journal of Healthcare Management, 57(6), 421-433.

Dean, K. (1989). Self-care components of lifestyles: the importance of gender, attitudes and the social situation. Social Science \& Medicine, 29(2), 137-152. doi:10.1016/0277-9536(89)90162-7.

Dexter, F., \& Lubarsky, D. A. (2004). Using length of stay data from a hospital to evaluate whether limiting elective surgery at the hospital is an inappropriate decision. Journal of clinical anesthesia, 16(6), 421-425. doi:10.1016/j. jclinane.2003.11.003.
Hollenbeak, C. S., Murphy, D. M., Koenig, S., Woodward, R. S., Dunagan, W. C., \& Fraser, V. J. (2000). The clinical and economic impact of deep chest surgical site infections following coronary artery bypass graft surgery. CHEST Journal, 118(2), 397-402.

Huang, Y. C., Hu, C. J., Lee, T. H., Yang, J. T., Weng, H. H., Lin, L. C., \& Lai, S. L. (2013). The impact factors on the cost and length of stay among acute ischemic stroke. Journal of Stroke and Cerebrovascular Diseases, 22(7), 152-158. doi:10.1016/j. jstrokecerebrovasdis.2012.10.014.

Mączyński, G. (2011). Restructuring and functioning of independent public health care providers (SPZOZs) on the basis of the Medical Activity Act: Between the Scylla of legal regulations and the Charybdis of economic inefficiency. Journal of Health Policy Insurance and Management, IX, 67-71.

Mapel, D. W., Mcmillan, G. P., Frost, F. J., Hurley, J. S., Picchi, M. A., Lydick, E., \& Spencer, M. D. (2005). Predicting the costs of managing patients with chronic obstructive pulmonary disease. Respiratory medicine, 99(10), 13251333. doi:10.1016/j.rmed.2005.03.001.

Medicare Program. (2003). Change in methodology for determining payment for extraordinarily high-cost cases (cost outliers) under the acute care hospital inpatient and long-term care hospital prospective payment systems. Fed Regist, 68(110), 34493-34515.

Ministry of Health. (2004). Debt of independent public health care. Information for the Parliamentary Committee on Health. Warszawa, 3-16.

Munoz, E., Zahtz, G., Lamantia, J., Chalfin, D., Lackner, R., \& Wise, L. (1989). Hospital resource consumption and outcome: route of admission and age for hospitalized otolaryngology patients. Archives of Otolaryngology-Head \& Neck Surgery, 115(1), 87-91. doi:10.1001/ archotol.1989.01860250089033.

OECD. (2016). OECD Health Statistics 2015. Retrieved April 11, 2016, from www.oecd. org/els/health-systems/health-data.htm.

Omachnonu, V. K., Suthummanon, S., Akcin, M., \& Asfour, S. (2004). Predicting length of stay for Medicare patients at a teaching hospital. Health Services Management Research, 17(1), 1-12. doi:10.1258/095148404322772688.

Perry, M., \& Alshurafa, M. (2010). Using admission from the emergency room to improve predictions of resource use and length of stay 


\section{Ekonomika a management}

for acute inpatient admissions in Ontario. BMC Health Services Research, 10(Suppl. 2), A21. doi:10.1186/1472-6963-10-S2-A21.

Pirson, M., Dramaix, M., Leclercq, P., \& Jackson, T. (2006). Analysis of cost outliers within APR-DRGs in a Belgian general hospital: Two complementary approaches. Health Policy, 76(1), 13-25. doi:10.1016/j.healthpol.2005.04.008.

Pirson, M., Martins, D., Jackson, T., Dramaix, M., \& Leclercq, P. (2006). Prospective casemixbased funding, analysis and financial impact of cost outliers in all-patient refined diagnosis related groups in three Belgian general hospital. The European Journal of Health Economics, 7(1), 55-65. doi:10.1007/s10198-005-0331-0.

Popesko, B., Papadaki, S., \& Novak, P. (2015). Cost and reimbursement analysis of selected hospital diagnoses via activity-based costing. E\&M Ekonomie a Management, 18(3), 50-60. doi:10.15240/tul/001/2015-3-005.

Raulinajtys-Grzybek, M. (2014). Cost accounting models used for price-setting of health services: an international review. Health Policy, 118(3), 341-353. doi:10.1016/j. healthpol.2014.07.007.

Rimar, J. M., \& Diers, D. (2006). Inpatient nursing, unit volume, length of stay, cost and mortality. Nursing Economics, 24(6), 298-307.

Rottger, J., Scheller-Kreinsen, D., \& Busse R. (2012). Patient - level hospital costs and length of stay after conventional versus minimally invasive total hip replacement: a propensitymatched analysis. Value in Health, 15(8), 999-1004. doi:10.1016/j.jval.2012.06.008.

Sackman, J. E., \& Citrin, L. (2014). Cracking down on cost outliers. Healthcare Financial Management, 68(3), 58-62.

Seshamani, M., \& Gray, A. (2004). Time to death and health expenditure: an improved model for the impact of demographic change on health care costs. Age and Ageing. 33(6), 556-561. doi:10.1093/ageing/afh187.
Simrova, J., Bartak, M., Vojtisek, R., \& Rogalewicz, V. (2014). The costs and reimbursements for lung cancer treatment among selected health care providers in the czech republic. E\&M Ekonomie a Management, 17(3), 74-85. doi:10.15240/tul/001/2014-3-007.

Soltes, V., \& Gavurova, B. (2014). The functionality comparison of the health care systems by the analytical hierarchy process method. E\&M Ekonomie a Management, 17(3), 100-116. doi:10.15240/tul/001/2014-3-007.

Stanisz, A. (2007). Accessible statistics course: using STATISTICA examples from medicine. Multidimensional analysis. (Przystępny kurs statystyki: z zastosowaniem STATISTICA PL na przykładach z medycyny. Analizy wielowymiarowe). StatSoft.

Sultz, H. A., \& Young, K. M. (2001). Healthcare USA Understanding Its Organization and Delivery. Gaithersburg, MD: Aspen.

Szetela, A., Lichwa, K., \& Korniejenko, K. (2011). Critical evaluation of the health care system in Poland, including the market reform of the Polish healthcare system. Zarządzanie Publiczne, 13, 49-64.

Taheri, P. A., Butz, D. A., \& Greenfield, L. J. (2000). Length of stay has minimal impact on the cost of hospital admission. J Am Coll Surg, 191(2), 123-130. doi:10.1016/S1072-7515(00)00352-5.

Uematsu, H., Kunisawa, S., Yamashita, K., \& Imanaka, Y. (2015). The Impact of Patient Profiles and Procedures on Hospitalization Costs through Length of Stay in CommunityAcquired Pneumonia Patients Based on a Japanese Administrative Database. PLoS ONE, 10(4). doi:10.1371/journal.pone.0125284.

Malgorzata Cyganska, Ph.D. University of Warmia and Mazury - Olsztyn Faculty of Economics Department of Finance and Banking m.cyganska@uwm.edu.pl 


\section{Abstract}

\section{ANALYSIS OF HIGH COST OUTLIERS IN A POLISH REFERENCE HOSPITAL Malgorzata Cyganska}

The growing financial problems of healthcare institutions contribute to the search of methods in properly distributing and clearly justifying resources. One of these is detecting outliers accounting for an important share of hospital costs. The aim of the study is to identify the factors facilitating identification of cost outliers in one of the Polish reference hospitals in northeast Poland. We have analyzed 4,570 patients. Cost analysis was done retrospectively using accountancy and statistical data from the hospital. To select the outliers, we used the interquartile method using the median and the interquartile distance. To evaluate the factors that influence the patient being a cost outlier, we considered: age, length of stay, gender, type of admission, reason of discharge, and type of department. Univariate analysis and multivariable logistic regression were used in the study. Our study revealed that the small percentage of the patients is responsible for the significant level of costs. The total cost outliers comprised $9 \%$ of the study sample. They accounted for almost $37 \%$ of total hospital costs, $40 \%$ of direct costs, and $34 \%$ of indirect costs. We discovered that age, gender, length of stay, reason of discharge, and type of department has a significant influence on being the cost outlier. The study revealed that the probability of being the CO increased more than 6 times for the surgical patients. This is consistent with the analysis of CO by ICD 10. The analysis revealed that almost all patients suffered from diseases related to high proportion of $\mathrm{CO}$, required surgery treatment. It is concluded that identifying the cost outliers can contribute to better knowledge by managers about the nature of the costs outliers and can be especially valuable in the financing systems where high costs outliers are separately paid.

Key Words: Direct costs, indirect costs, cost outliers, hospital management.

JEL Classification: I150, M410.

DOI: 10.15240/tul/001/2017-4-005 